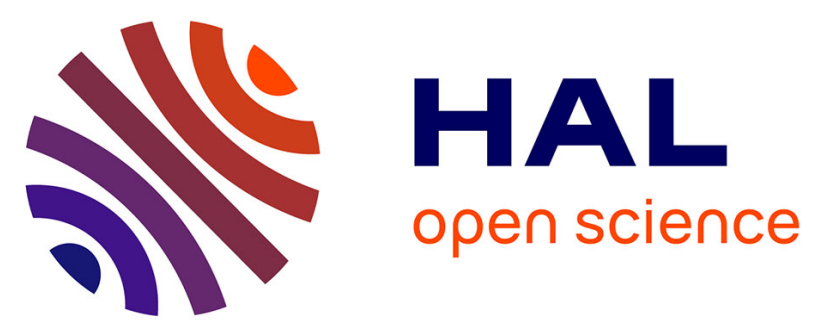

\title{
OPERATIONAL PERFORMANCES \\ DEMONSTRATION OF POLYMER-CERAMIC EMBEDDED CAPACITORS FOR MMIC APPLICATIONS
}

Isabelle Bord-Majek, Philippe Kertesz, Julie Mazeau, Daniel Caban-Chastas, Bruno Levrier, Laurent Bechou, Yves Ousten

\section{To cite this version:}

Isabelle Bord-Majek, Philippe Kertesz, Julie Mazeau, Daniel Caban-Chastas, Bruno Levrier, et al.. OPERATIONAL PERFORMANCES DEMONSTRATION OF POLYMER-CERAMIC EMBEDDED CAPACITORS FOR MMIC APPLICATIONS. IEEE Transactions on Components, Packaging and Manufacturing Technology, 2011, 1 (9), pp.1473-1479. hal-00641070

\author{
HAL Id: hal-00641070 \\ https://hal.science/hal-00641070
}

Submitted on 14 Nov 2011

HAL is a multi-disciplinary open access archive for the deposit and dissemination of scientific research documents, whether they are published or not. The documents may come from teaching and research institutions in France or abroad, or from public or private research centers.
L'archive ouverte pluridisciplinaire HAL, est destinée au dépôt et à la diffusion de documents scientifiques de niveau recherche, publiés ou non, émanant des établissements d'enseignement et de recherche français ou étrangers, des laboratoires publics ou privés. 


\title{
OPERATIONAL PERFORMANCES DEMONSTRATION OF POLYMER- CERAMIC EMBEDDED CAPACITORS FOR MMIC APPLICATIONS
}

\author{
Isabelle Bord-Majek*, Philippe Kertesz**, Julie Mazeau**, Daniel Caban-Chastas**, \\ Bruno Levrier*, Laurent Bechou* and Yves Ousten* Member, IEEE \\ * IMS Laboratory, Université de Bordeaux - UMR 5218 CNRS \\ 351 Cours de la Libération, 33405 Talence Cedex, France \\ ** THALES Systèmes Aéroportés, Centre Nungesser CN/401 \\ 2 avenue Gay-Lussac, 78851 Elancourt, France
}

\begin{abstract}
Embedded passives are becoming increasingly important for the manufacture of highly integrated electronic boards and packages. The need for embedded passives emerges from the growing consumer demand for product miniaturization thus requiring smaller components and space efficient packaging. This can be realized by replacing discrete components that demands a higher volume than embedded passives. Embedded passives have already been investigated in the last few years. However nowadays used dielectric materials have to be optimized in order to improve the performances of the passive components in terms of dielectric behaviour and reliability. The most promising candidates for dielectric materials applied for embedded passives are polymerceramic nanocomposites. In this paper the robustness of embedded capacitors using such commercial dielectrics regarding the environmental conditions (temperature and humidity) is studied. Microwave measurements performed on an embedded structure design for Low Noise Amplifier (LNA) MMIC decoupling allow to demonstrate clearly the capacity of this new technology.
\end{abstract}

\section{Keywords}

Embedded capacitors, polymer-ceramic dielectrics, robustness, operational microwave performance 


\section{INTRODUCTION}

Electronic board and package miniaturization imply the size reduction of bulky and numerous passive components. It is reasonable to expect passive component densities of $20-30$ passives $/ \mathrm{cm}^{2}$ [1]. Although surface mounted devices (SMD) components can be provided as very small passives, their reflow process onto the printed circuit board (PCB) is very tricky limiting thus their operational reliability [2].

Many studies have been performed on the recurring problem of the reliability of ceramic capacitors in all shapes and sizes. It is now widely known that the increase of the stress is caused by the mismatch of the thermal expansion coefficient and the thermal conductivity between the ceramic dielectric, the terminations, the solder, the copper land and the substrate. During cooling, the difference of dissipation due to heat flow between these elements creates important contraction or compression constraints on the different materials. Any concentration of stress can induce cracks (fracture of the leads, shear and fracture of the solder joint, lifting of the copper lands) or cause failure of the assembly during operational use of the components [3].

In order to overcome the risk of early failures related to ceramic capacitors, an interesting approach consists in their replacement with passive layers embedded in a PCB substrate (as FR4 or KAPTON FLEX) during the PCB manufacturing process. The integration of passive layers into the PCB might lead to both increase the integration density and improve the reliability. Moreover the embedded capacitor can be located close to the active component reducing the associated parasitic inductances that are linked to its interconnects.

To be used as dielectric layer for embedded capacitors, the material must:

- $\quad$ present the following dielectric properties: high dielectric constant and low dielectric losses over a broad frequency range,

- $\quad$ be deposited as thin layer (roughly around $10 \mu \mathrm{m}$ ),

- be in accordance with PCB temperature process $\left(\sim 200^{\circ} \mathrm{C}\right.$, high pressure processes),

- $\quad$ provide a thermal (high glass transition temperature Tg) and mechanical stability, and

- be low-cost.

In this way polymer-ceramic composites are promising materials for embedded capacitors because they combine the high dielectric permittivity of ceramic powders and the processability and flexibility of polymers 
(in particular low temperature processing) [4]. In this paper we focus only on such commercial dielectric materials.

\section{EMBEDDED CAPACITORS BASED ON COMMERCIAL POLYMER- CERAMIC DIELECTRICS}

Embedded capacitors are made of a dielectric material layer deposited between two metal layers (usually copper foils) that are buried in the PCB. Inorganic dielectric materials commonly used for discrete capacitors are partly replaced by organic polymers. Polymer-ceramic composites are expected to be the major candidate as dielectric layer for embedded capacitors because such composite materials present both characteristics of the processibility of polymers and a high dielectric constant of inorganic materials as barium titanate $[5,6]$.

The polymer (usually epoxy or polyimide) is filled with high dielectric constant particles (usually $\mathrm{BaTiO}_{3}$ according to EDX analysis presented Figure 1) modifying the organic film. Such dielectric composites commercially available as pre-fab laminates are studied later [7, 8, 9].

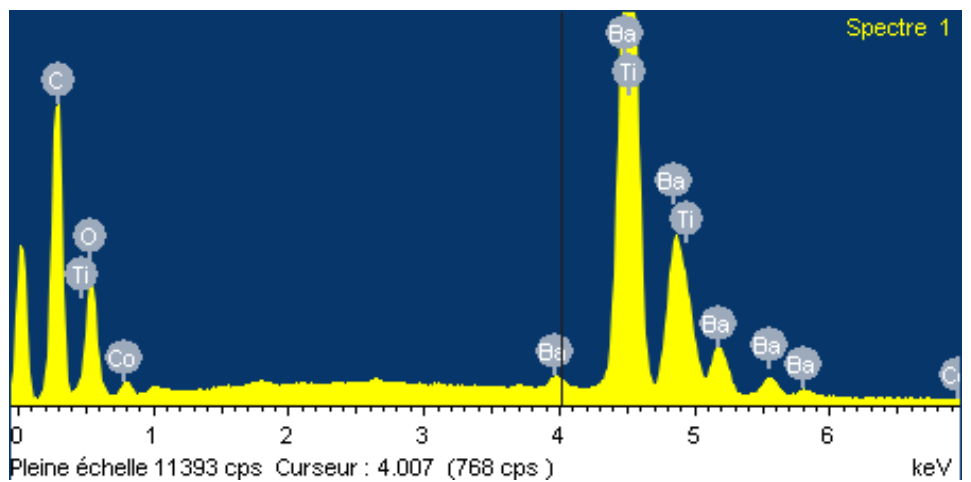

Figure 1: EDX analysis of a commercial dielectric layer based on $\mathrm{BaTiO}_{3}$ particles (BC8T-FaradFlex ${ }^{\circledR}$ material from Oak-Mitsui)

Embedded capacitors based on such dielectrics are partly made with plastic materials subjected to both moisture and temperature. In order to perform a robustness study, the impact of temperature and humidity on embedded capacitors based on commercial pre-fab laminates is studied.

\section{ENVIRONMENTAL CONDITIONS INFLUENCE}

The pre-fab laminates were buried in a conventional PCB by a PCB manufacturer according to the dielectric datasheet. 


\subsection{TEMPERATURE INFLUENCE ON CAPACITANCE}

The temperature is supposed to be the more critical parameter for embedded capacitors based on a polymerceramic material. Capacitance measurements versus frequency were carried out using the impedance meter HP 4192A and the test fixture HP 16034E in the frequency range [1kHz, $1000 \mathrm{kHz}]$.

Figure 2 shows the capacitance variation versus frequency in the temperature range $\left[25^{\circ} \mathrm{C}, 150^{\circ} \mathrm{C}\right]$ for an OakMitsui embedded capacitor based on the BC16T-FaradFlex ${ }^{\circledR}$ material. The electrode area of the studied capacitor is $6.0 \times 6.0 \mathrm{~mm}^{2}$ and the dielectric thickness is $16 \mu \mathrm{m}$.

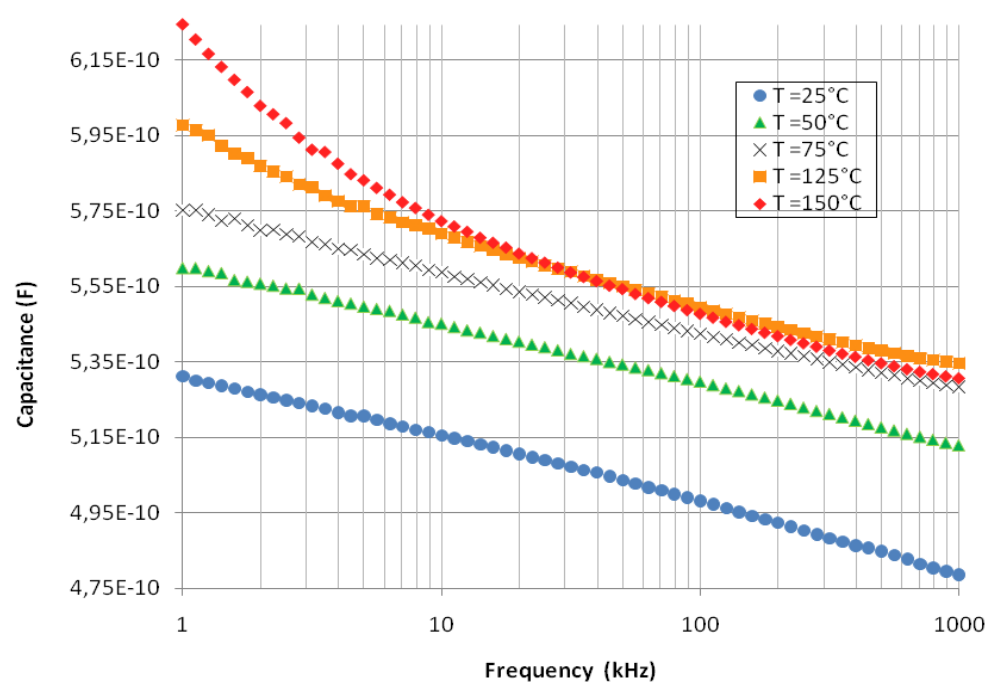

Figure 2: Capacitance variation versus frequency in the temperature range $\left[25^{\circ} \mathrm{C}, 150^{\circ} \mathrm{C}\right]$ for an OakMitsui embedded capacitor based on the BC16T-FaradFlex ${ }^{\circledR}$ material

Whatever the temperature, the capacitance decreases as increases the frequency due to the drop of the relative permittivity $\varepsilon_{r}(\omega)$ with frequency. The thermal expansion coefficient (CTE) of such commercial dielectrics is about $20.10^{-6} \mathrm{C}^{-1}$. So the dimensional expansion is about $0.04 \mu \mathrm{m}$ in the studied temperature range $\left[25^{\circ} \mathrm{C}\right.$, $\left.150^{\circ} \mathrm{C}\right]$ that is negligible compared to the material thickness $(16 \mu \mathrm{m})$.

The capacitance $C(\omega)$ is linked to $\varepsilon_{r}(\omega)$ by the following equation:

$C(\omega)=\frac{\varepsilon_{r}(\omega) \varepsilon_{0} S}{d}$

where $\omega$ is the excitation frequency, $\varepsilon_{0}$ the vacuum permittivity, $S$ the electrode area and $d$ the dielectric thickness. 
Moreover the capacitance increases with temperature due to the increase of the relative permittivity $\varepsilon_{r}(\omega)$ with temperature. A change of the behaviour of the capacitance is observed after $125^{\circ} \mathrm{C}$ due to glass transition of the dielectric.

\subsection{THERMAL STORAGE}

In order to perform a robustness study, similar embedded capacitors as previously (made of the same nature of dielectric) were placed in a climatic chamber for hours. The electrode area of the studied capacitors is $1.0 \times 1.0$ $\mathrm{mm}^{2}$ and the dielectric thickness is $8 \mu \mathrm{m}$.

Figure 3 shows the capacitance variation versus frequency after the first exposure hours to (a) $85^{\circ} \mathrm{C}$ and (b) $150^{\circ} \mathrm{C}$ for an Oak-Mitsui embedded capacitor based on the BC8T-FaradFlex ${ }^{\circledR}$ material.

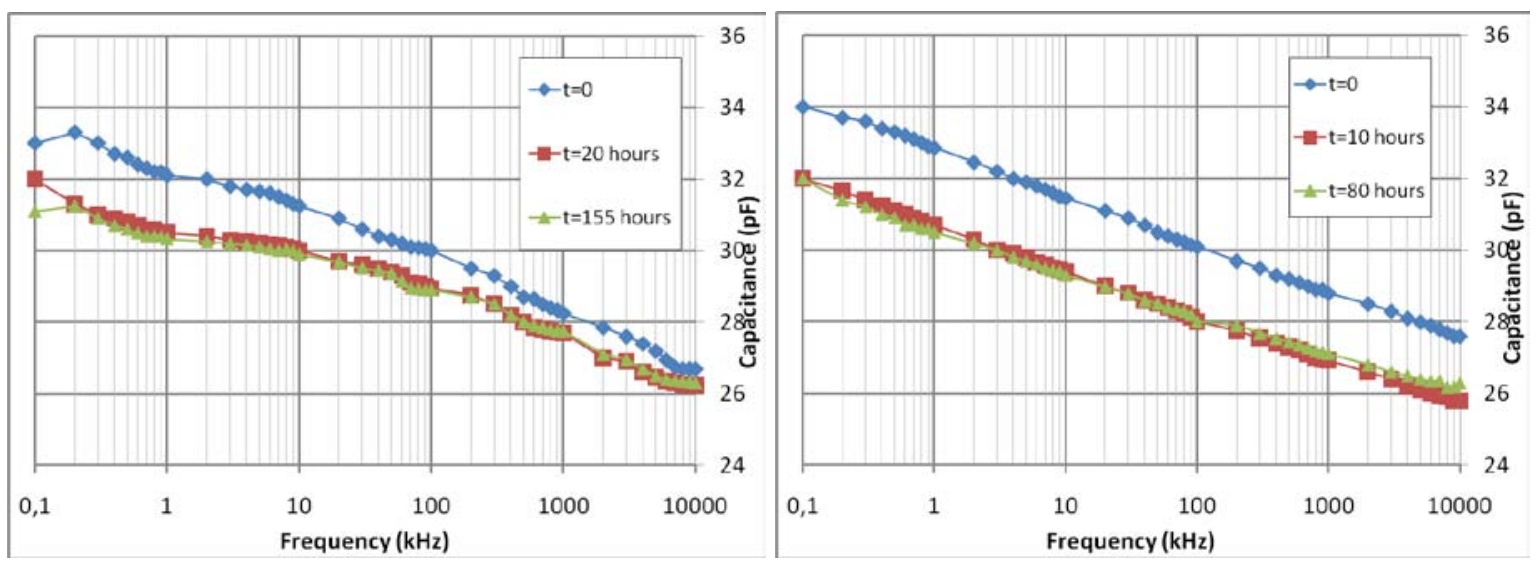

(a) $85^{\circ} \mathrm{C}$

(b) $150^{\circ} \mathrm{C}$

Figure 3: Capacitance variation versus frequency after various exposure times to (a) $85^{\circ} \mathrm{C}$ and (b) $150^{\circ} \mathrm{C}$ for an Oak-Mitsui embedded capacitor based on the BC8T-FaradFlex ${ }^{\circledR}$ material

Whatever the temperature, the capacitance decreases with exposure time. At ambient temperature, the dielectric material contains a little part of water. After exposure to $85^{\circ} \mathrm{C} / 150^{\circ} \mathrm{C}$, water is evaporated. Water permittivity is higher than dielectric one whatever the frequency. So the material permittivity and then the capacitance decrease after exposure to $85^{\circ} \mathrm{C} / 150^{\circ} \mathrm{C}$. The behaviour is similar at $85^{\circ} \mathrm{C}$ and $150^{\circ} \mathrm{C}$. However the capacitance decrease is accelerated at $150^{\circ} \mathrm{C}$ : the same variation is observed at $150^{\circ} \mathrm{C}$ after $80 \mathrm{~h}$ and at $85^{\circ} \mathrm{C}$ after $155 h$.

Figure 4 presents the capacitance variation versus exposure time at $150^{\circ} \mathrm{C}$ at different frequencies after drying for the Oak-Mitsui embedded capacitor based on the BC8T-FaradFlex ${ }^{\circledR}$ material. 


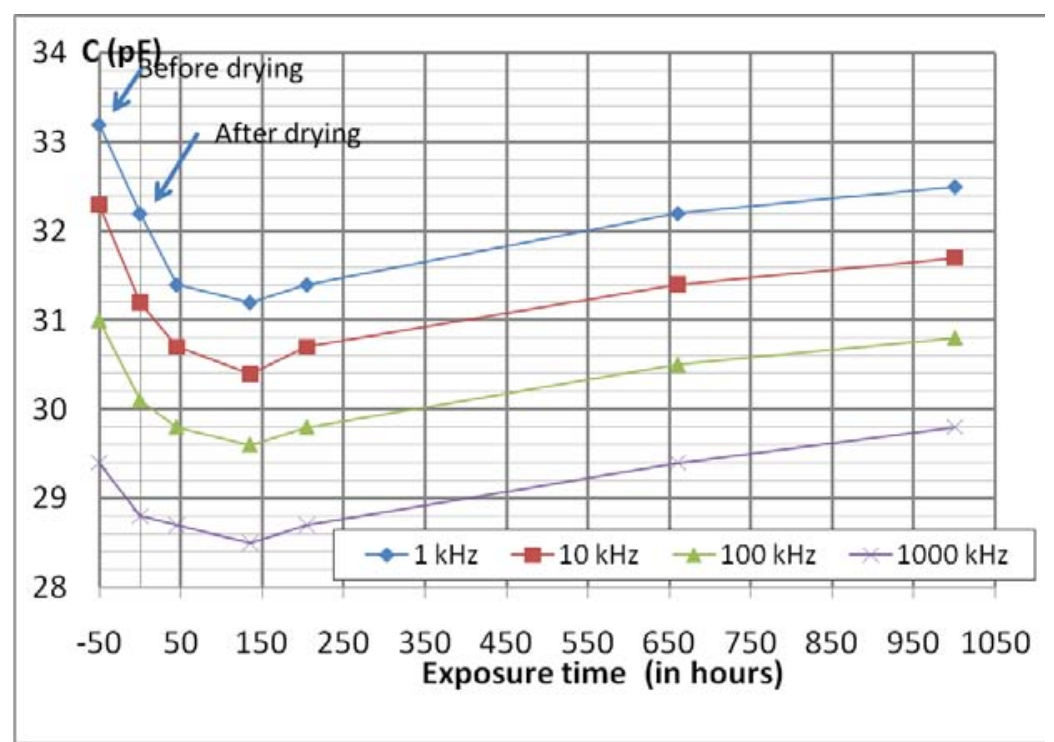

Figure 4: Capacitance variation versus exposure time at $150^{\circ} \mathrm{C}$ at different frequencies for an Oak-Mitsui embedded capacitor based on the BC8T-FaradFlex ${ }^{\circledR}$ material

After drying, the capacitance decreases due to water evaporation. A maximal capacitance variation of only $6 \%$ is observed after $135 \mathrm{~h}$.

A gradual slope change is observed with exposure time (especially at high frequency). After 135h the capacitance increases. This phenomenon may be correlated with a modification of the dielectric material during thermal ageing.

\subsection{HUMIDITY STORAGE}

Similar embedded capacitors (electrode area $1.0 \times 1.0 \mathrm{~mm}^{2}$ and dielectric thickness $8 \mu \mathrm{m}$ ) were stored in a climatic chamber with humidity control for hours. Capacitance measurements versus frequency were carried out after various exposure times to $85^{\circ} \mathrm{C} / 85 \% \mathrm{RH}$ (Relative Humidity). Figure 5 presents the capacitance variation versus exposure time to $85^{\circ} \mathrm{C} / 85 \% \mathrm{RH}$ at different frequencies for the Oak-Mitsui embedded capacitor based on the BC8T-FaradFlex ${ }^{\circledR}$ material. 


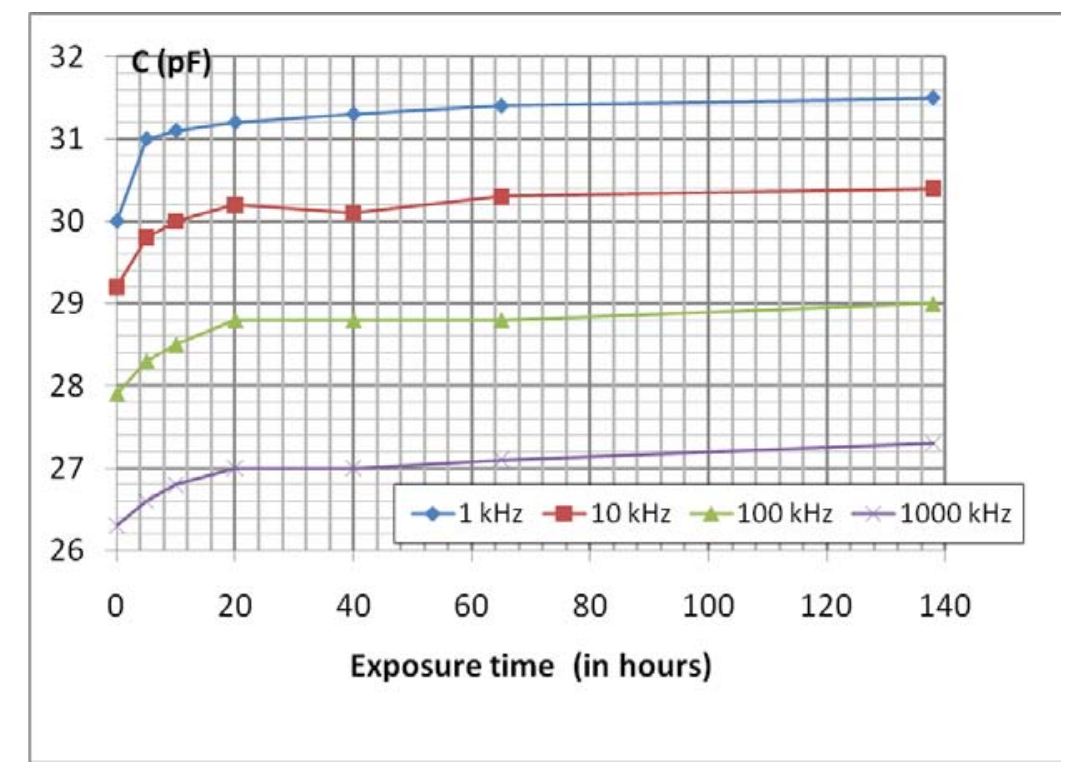

Figure 5: Capacitance variation versus exposure time to $85^{\circ} \mathrm{C} / 85 \% \mathrm{RH}$ at different frequencies for an OakMitsui embedded capacitor based on the BC8T-FaradFlex ${ }^{\circledR}$ material

The capacitance increases with exposure time because of water absorption by the material (water permittivity higher than polymer/ceramic permittivity). After 138 hours, no significant variation is observed. The maximal capacitance variation is about $5 \%$.

\section{COMPARISON WITH DISCRETE CAPACITORS}

\subsection{ENVIRONMENTAL CONDITIONS INFLUENCE}

The maximum exposure time at high temperature, number of reflow solder cycles or re-work cycles are not limited by ceramic capacitors but by the laminate assembly and the plastic moulded components quality. Generally defects induced on ceramic capacitors are due to manufacturing process and reflow problems. This kind of defects can generate failures during components operation. For example, in a previous study, we tested two lots of 25X7R 0805 ceramic capacitors 47pF using impedance spectroscopy. After thermal ageing $\left(150^{\circ} \mathrm{C}\right.$ during 1000h), a significant drift of the capacitance was systematically observed (nearly 20\%) and some components were found defective because of cracks [10].

In the case of embedded capacitors based on polymer/ceramic dielectric, a 6\% maximal capacitance variation is observed after $135 \mathrm{~h}$. After $1000 \mathrm{~h}$, the capacitance variation is only 3\%, clearly lower than ceramic capacitors one (15\%). 
Humidity is not a recognized factor of failure of ceramic capacitors. Humidity may be dangerous for the metal terminations that make up the electrodes but not for the dielectric material. When both precious metal electrode and base metal electrode (BME) capacitors were subjected to autoclave $\left(121^{\circ} \mathrm{C} / 100 \% \mathrm{RH}\right)$ testing after $500 \mathrm{~h}$, it was found that the precious metal capacitors aged (average capacitance degraded less than $3 \%$ from their starting values), but the BME capacitors degraded to below the $-30 \%$ specification limit [11]. This problem is reduced in embedded capacitors because the electrodes are protected by the PCB. Our study showed a maximal capacitance variation with humidity of about $5 \%$.

\subsection{INTERNAL STRESS}

Embedded passives are supposed to be more reliable than discrete passives as they do not require solder joints. The shear stress (due to CTE mismatch) is the main cause of delaminations and cracks in the case of discrete capacitors. For the reliability point of view, it is essential to know the stress at the different interfaces in embedded capacitors.

The shear stress values inside the PCB were estimated using the analytical program CRITIDEL from EURELNET [12] at the interfaces:

- $\quad$ PCB-Copper

- $\quad$ Copper-Dielectric (i.e. Figure 6)

The values of mechanical properties necessary to the analytical calculation of the stress are summarized in the Table 1.

\begin{tabular}{|c|c|c|}
\hline Material & Young Modulus (GPa) & CTE (ppm. $\mathbf{C}^{\mathbf{- 1}}$ ) \\
\hline PCB & 15 & 14 \\
\hline Copper & 100 & 17 \\
\hline Dielectric & 1.3 & 32 \\
\hline
\end{tabular}

Table 1: Mechanical properties of materials [12]

Figure 6 presents the calculated shear stress values versus the thickness of the dielectric layer. 

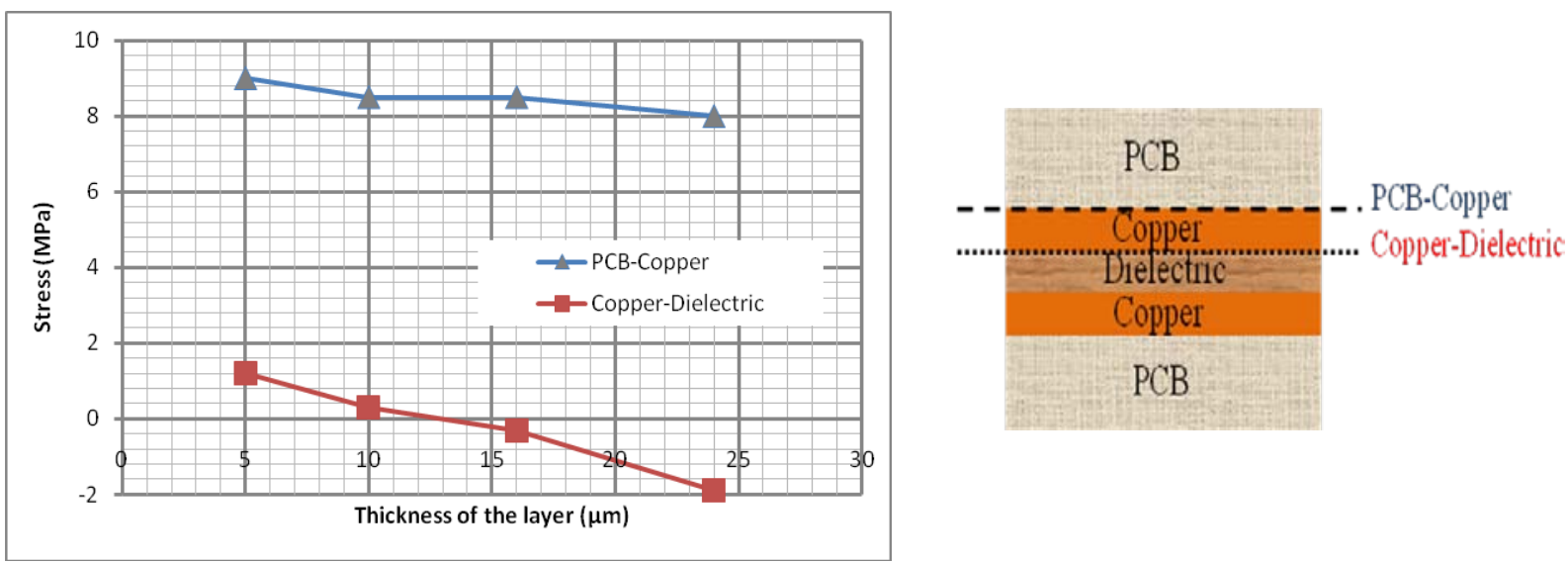

Figure 6: Shear stress values between PCB-Copper and Copper-Dielectric versus dielectric thickness calculated using CRITIDEL

The embedded capacitors (PCB-Copper interface) undergo a stress domain from $8 \mathrm{MPa}$ to $10 \mathrm{MPa}$ that is less critical than the one of capacitors reflowed on a PCB (200 MPa to $300 \mathrm{MPa}$ [13]).

The behaviour and the robustness of isolated embedded capacitors are now checked. But what about the operational microwave performance of such components ?

\section{OPERATIONAL MICROWAVE PERFORMANCE}

\subsection{EMBEDDED CAPACITORS FUNCTIONAL TEST VEHICLE}

In the framework of HIFAP program (PIDEA+), we designed an embedded structure for « real » MMIC decoupling measurements: the Low Noise Amplifier (LNA) UMS (United Monolithic Semiconductors) CHA3023 could be easily implemented with such embedded capacitors and it could be then easy to clearly demonstrate the potential of this new technology. In this way, two equivalent versions of the LNA were manufactured:

- a version with an embedded capacitor as decoupling capacitor (using an organic substrate)

- a version with a discrete ceramic capacitor as decoupling capacitor.

\subsection{EMBEDDED DESIGNS EVALUATION}


S parameters measurements were carried out using the test set network analyzer Agilent 85110A (connected to HF probes) in the frequency range $[2,18 \mathrm{GHz}]$ for both previous LNA versions. The following parameters were checked:

- S11 input return loss

- S22 output return loss

- S21 output insertion loss (LNA’s gain).

Figure 7 presents the LNA Gain (S21 output insertion loss) using (a) ceramic discrete capacitors and (b) embedded capacitors as decoupling capacitor.

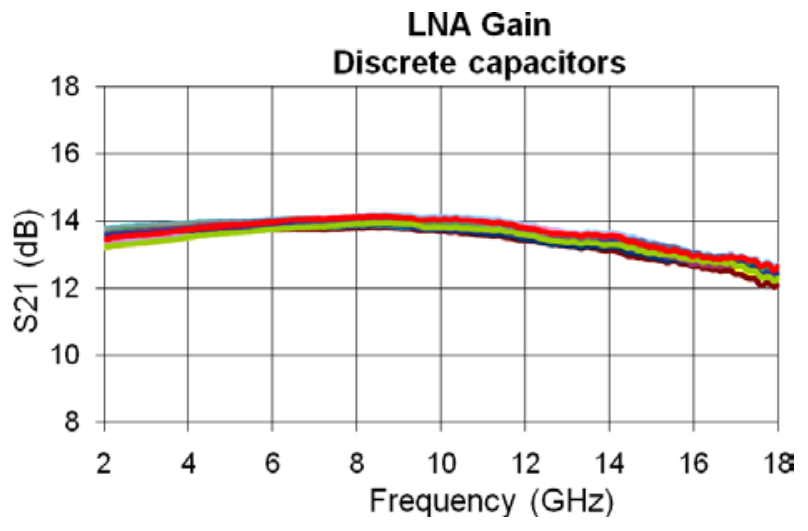

(a)

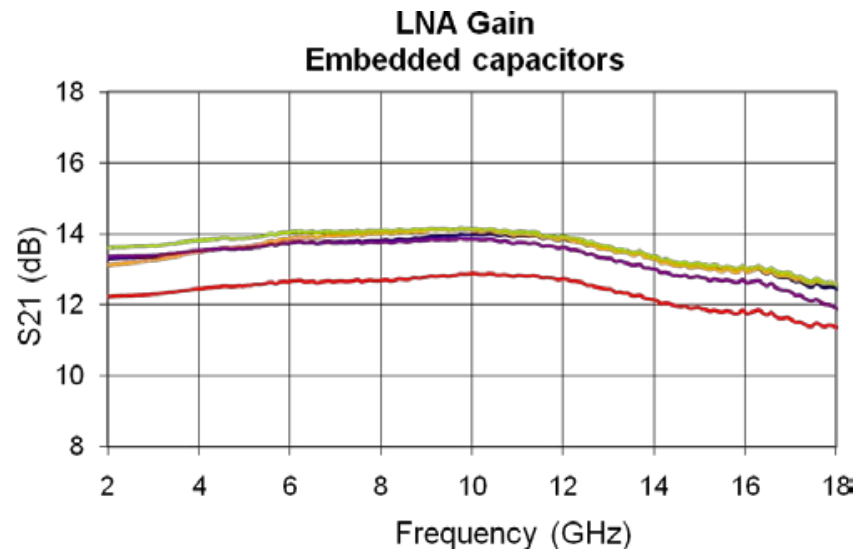

(b)

Figure 7: LNA Gain measurements using discrete decoupling capacitors and using embedded decoupling capacitors

The LNA Gain is very similar in discrete and embedded capacitors configuration (around 13dB).

Figure 8 presents the LNA return losses (S11 and S22) using (a) ceramic discrete capacitors and (b) embedded capacitors. 

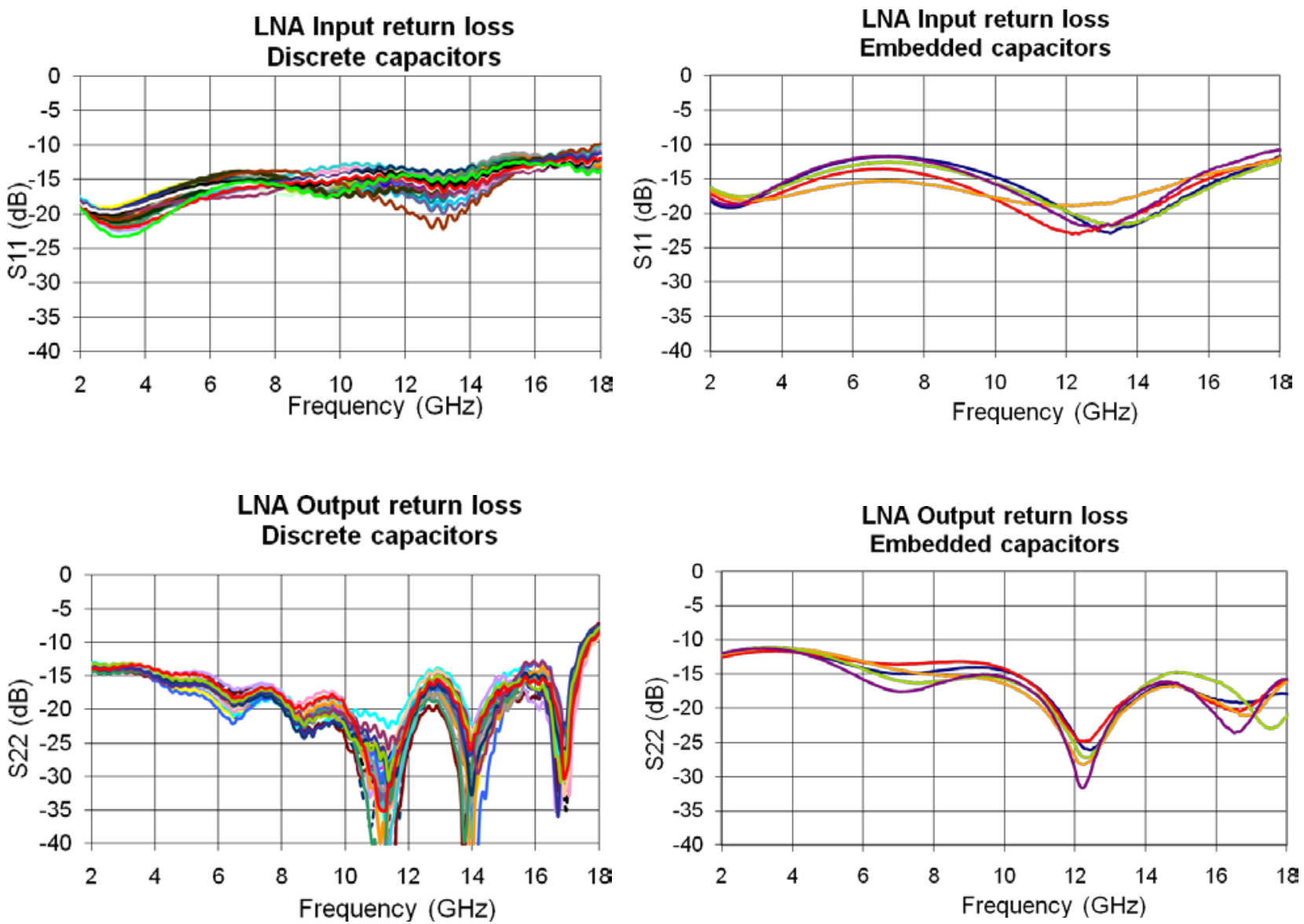

(a)

(b)

Figure 8: LNA Return losses measurements using (a) discrete decoupling capacitors and (b) embedded decoupling capacitors

The LNA return losses are also very similar in discrete and embedded capacitors configuration (around -15dB).

The oscillations are different in both cases (embedded en discrete capacitors configurations) because of the difference in impedance due to the design. However there is no impact on the LNA Gain.

The previous results show that the concept is validated at room temperature.

\subsection{Thermal stability}

No difference in LNA behaviour was observed for both vehicles (discrete and embedded capacitors configuration) at room temperature.

The previous circuits were then considered for measurement under high/low temperature in order to check decoupling thermal stability. 
Measurement was performed using the following method (detailed in Figure 9) in the temperature range [-40, $\left.+80^{\circ} \mathrm{C}\right]$.

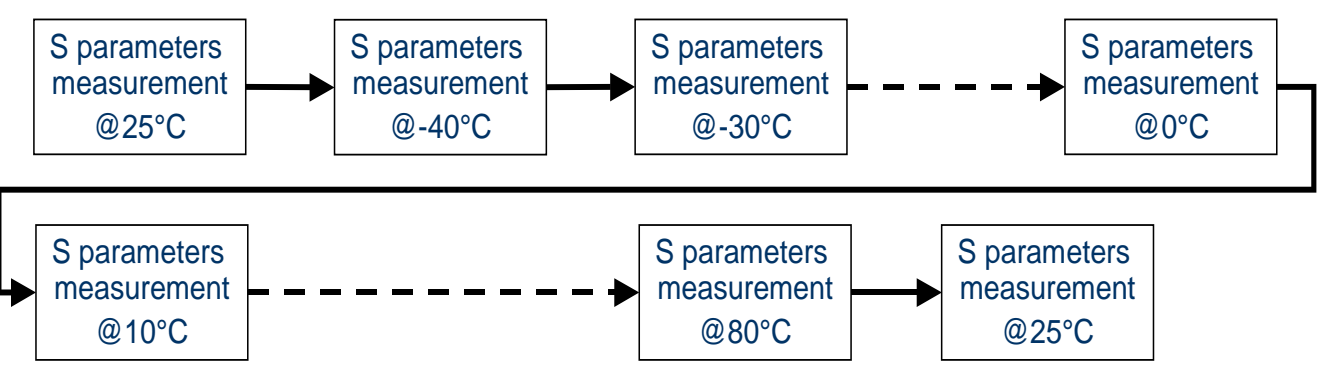

Figure 9: Thermal stability measurement method

This way we could assess potential S parameters values hysteresis that would indicate that the embedded capacitors are not thermally stable.

Figure 10 presents the LNA return losses using embedded capacitors in the temperature range $\left[-40,+80^{\circ} \mathrm{C}\right]$.

LNA Input return loss

$\left[-40,+80^{\circ} \mathrm{C}\right]$

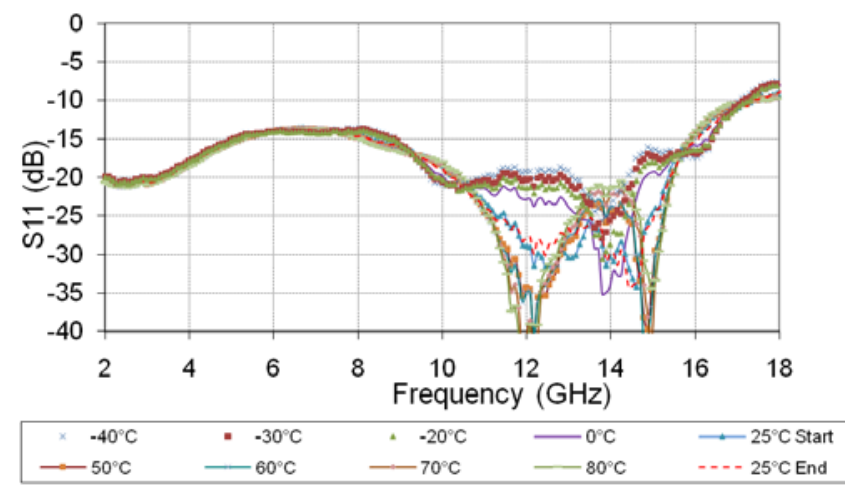

(a)
LNA Output return loss

$\left[-40,+80^{\circ} \mathrm{C}\right]$

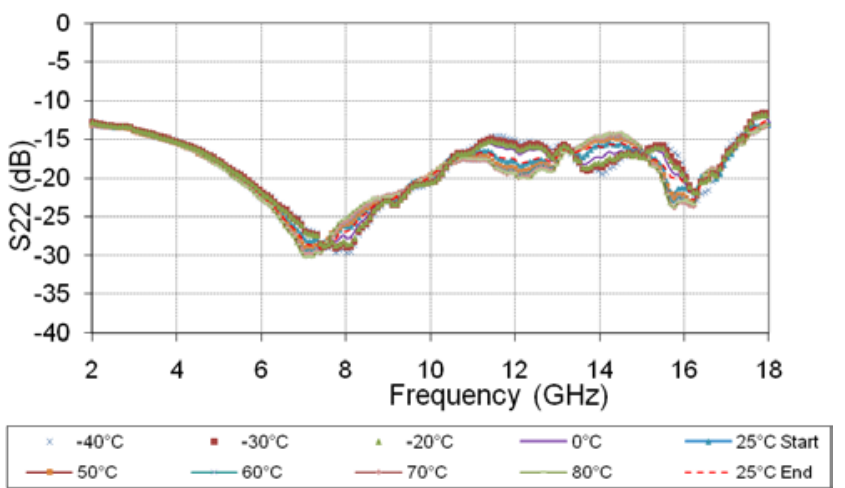

(b)

Figure 10: LNA (a) input Return loss and (b) output Return loss measurements using embedded decoupling capacitors in the temperature range $\left[-40,+80^{\circ} \mathrm{C}\right]$

No significant modification of the LNA Return Losses is noticed in respect to temperature.

Figure 11 presents the LNA Gain using embedded capacitors in the temperature range $\left[-40,+80^{\circ} \mathrm{C}\right]$. 


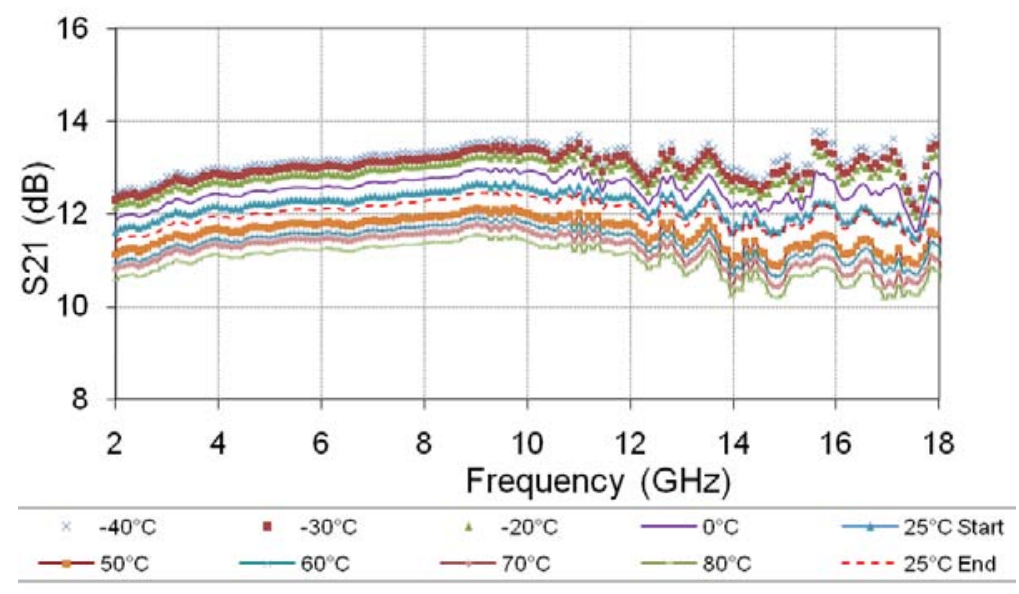

Figure 11: LNA Gain versus frequency using embedded decoupling capacitors in the temperature range

$$
\left[-40,+80^{\circ} \mathrm{C}\right]
$$

A change is noticed in the LNA Gain with temperature: the S21 parameter decreases with temperature.

Figure 12 presents the LNA Gain variation compared to the reference gain at $25^{\circ} \mathrm{C}$ with embedded capacitors in the temperature range $\left[-40,+80^{\circ} \mathrm{C}\right]$.

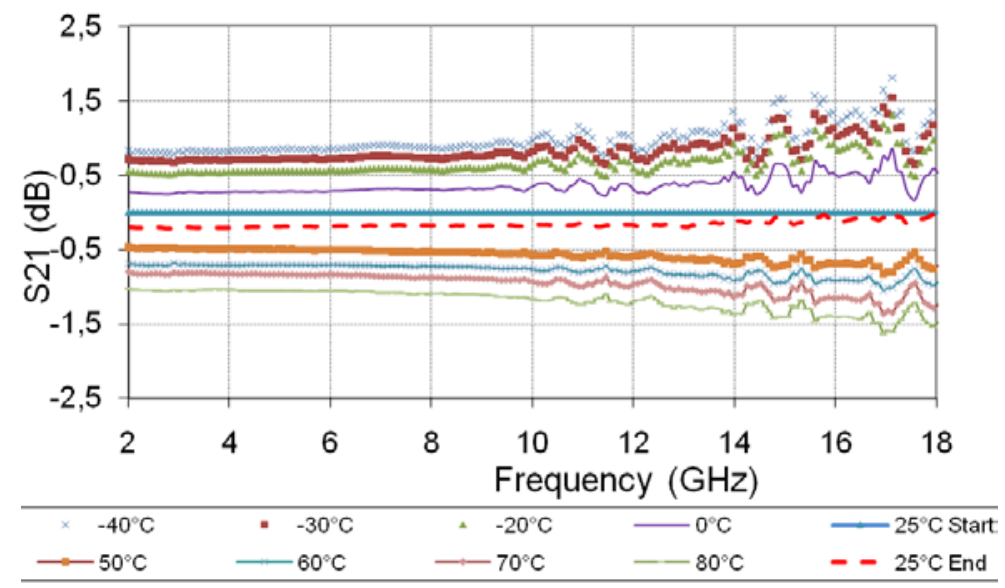

Figure 12: LNA Gain variation compared to the reference gain at $25^{\circ} \mathrm{C}$ with embedded decoupling capacitors in the temperature range $\left[-40,+80^{\circ} \mathrm{C}\right]$

According to the LNA (UMS, CHA3023) datasheet, the S21 (LNA gain) temperature sensitivity is actually modified according the following rule: $-0.03 \mathrm{~dB} /{ }^{\circ} \mathrm{C}$.

According to Figure 12, measurements are fully compliant with datasheet:

- $\quad(\mathrm{S} 21)_{80{ }^{\circ} \mathrm{C}}=(\mathrm{S} 21)_{25^{\circ} \mathrm{C}}-1.65 \mathrm{~dB}$

- $\quad(\mathrm{S} 21)_{-40^{\circ} \mathrm{C}}=(\mathrm{S} 21)_{25^{\circ} \mathrm{C}}+1.95 \mathrm{~dB}$ 
So the S21 variation is related to the LNA intrinsic thermal sensitivity and not to the embedded capacitors.

Moreover the S21 is stable after thermal cycling which implies that temperature effect is reversible. The assessed LNA operates properly within the frequency band and with respect to temperature.

The stability of embedded capacitors is now achieved representing a major breakthrough for microwave packaging.

\section{CONCLUSIONS}

Capacitive laminates commercially available were studied. Theoretical performance of embedded capacitors using organic polymer dielectric was first assessed:

- the capacitance decreases after thermal exposure $(\leq 6 \%)$ because of water evaporation.

- $\quad$ the capacitance increases after humidity exposure $(\leq 5 \%)$ due to water absorption.

Operational performance of embedded capacitors using organic polymer dielectric was then checked and compared to discrete capacitors one. Finally it was demonstrated that the commercial laminates could be used efficiently to replace discrete decoupling capacitors for microwave packaging and with no reliability issues (with respect to moisture and temperature) to be foreseen.

With the added benefits of elimination of solder joints, inventory, assembly and rework with respect to their surface mounted counterparts, embedded ceramic capacitors provide a very convincing and compelling option to meet the ever increasing need for miniaturization and improve performance in modern electronic designs.

Although embedded capacitors are promising, the range of available capacitance values is not sufficient for the moment (close to 0.5 to $2 \mathrm{nF} / \mathrm{cm}^{2}$ ). In order to reduce the size of the basic capacitor and generate a larger range of capacitance values (20 to $200 \mathrm{nF} / \mathrm{cm}^{2}$ ), two ways are currently explored:

- the synthesis of materials with higher values of dielectric permittivity (high-k materials) over a broad frequency range with respect to PCB manufacturing process requirements,

- $\quad$ and the reduction of the dielectric layer $(<8 \mu \mathrm{m})$ which induces a good processability of the material (printable formulation).

In this way, polymer-ceramic nanomaterials used to make embedded capacitors must be improved. 


\section{ACKNOWLEDGEMENTS}

The authors gratefully acknowledge Jean-Yves Gondouin from Elvia-Lithos as PCB manufacturer and the different manufacturers (in particular Oak Mitsui) which provide us materials for the tests within research and development programs as HIFAP (PIDEA+), PROCURE FP5 and AMELIE FP6.

\section{REFERENCES}

[1] S. Manian Ramkumar, Reza Ghaffarian,1, Arun Varanasi, "Lead-free 0201 manufacturing, assembly and reliability test results”, Microelectronics Reliability (46) 244-262, 2006

[2] Y. Ousten, I. Bord, C. Blot, B. Levrier, L. Bechou and P. Kertesz, "Environmental conditions influence on embedded capacitors - Comparison with discrete capacitors”, CARTS USA 2010, New Orleans, 15-18 March, 2010, 31-41

[3] L. Bechou, Y. Ousten and N. Xiong, "Simulation of assembly generated constraints on ceramic capacitors during SMT processing and size optimization of the capacitor by design of experiments” Hybrid circuit 1993

[4] H. Windlass, P. M. Raj, D. Balaraman, S. K. Bhattacharya and R.R. Tummala, “Colloidal processing of polymer ceramic nanocomposite integral capacitors”, IEEE Trans. Electron. Pack. Manuf. (26) 100-105, 2003

[5] Long Wu, Ming-Cheng Chure, King-Kung Wu, Wen-Chung Chang, Ming-Ju Yang, Wei-Kuo Liu, MenqJion Wu, “Dielectric properties of barium titanate ceramics with different materials powder size”, Ceramic International (35) 957-960, 2009

[6] Sea-Fue Wang, Yuh-Ruey Wang, Kuo-Chung Cheng, Yu-Ping Hsaio , “Characteristics of polyimide/barium titanate composite films”, Ceramics International (35) 265-268, 2009

[7] http://www2.dupont.com/Interra/en_US/

[8] http://www.mitsui-kinzoku.co.jp/en/news/pdf/2008/topics_081001.pdf

[9] $\underline{\text { http://solutions.3m.com/wps/portal/3M/en_WW/electronics/home/productsandservices/products/Microinterc }}$ onnectSolutions/EmbeddedCapacitanceMaterial/ 
[10] Y. Ousten, L. Bechou, F. Verdier, B. Levrier, I. Bord and B. Carbonne, "Different approaches to packaging reliability”, European Electronics Assembly Reliability Summit, Tallinn, Estonia, 22-24 October, 2008

[11] D.N. Donahoe, M. Pecht, I.K. Lloyd , S. Ganesan , “Moisture induced degradation of multilayer ceramic capacitors”, Microelectronics Reliability (46) 400-408, 2006

[12] https://www.eurelnet.org (European Reliability Network)

[13] Y. C. Chan, F. Yeung and T. S. Mok, "Failure analysis of miniaturized multilayer ceramic capacitors in surface mount printed circuit board assemblies”, Journal of Materials Science: Materials in Electronics 5, Number 1, 1994 